\title{
Ricardo Palma, ¿dueño de un semanario?
}

\author{
Alberto Varillas Montenegro \\ Academia Peruana de la Lengua \\ Instituto Riva Agüero, Lima - Perú. \\ varillas.alberto@gmail.com
}

\section{Resumen}

Desde muy joven, Ricardo Palma manifestó especial interés por el periodismo. Sin embargo, los pocos trabajos que se han contraído al estudio de Palma como periodista no han insistido en su participación en el semanario El Burro. El único ejemplar que se conoce de esta publicación se encuentra sumamente deteriorado como consecuencia del incendio que en 1943 destruyó la Biblioteca Nacional, especialmente su hemeroteca. Este trabajo estudia brevemente El Burro y, a propósito de él, evalúa la importancia que este tipo de publicaciones tuvo dentro de la vida peruana de mediados del siglo XIX.

Palabras clave: Historia y literatura peruanas del siglo XIX, Ricardo Palma, periodismo peruano

\section{Abstract}

Ricardo Palma made his firsts attemps as a journalist while still attending high school. However, only few papers have been devoted to his work as such and none of them has been able to study his weekly newspaper El Burro, given the fact that the only existing copy was seriously damaged in the 1943 fire that destroyed the Peruvian National Library, especially its newspaper archives. This work deals with El Burro and emphasizes the importance that this type of publications held within the Peruvian 19th century life.

Keywords: 19th century Peruvian History and Literature, Ricardo Palma, Peruvian journalism 
Alberto Varillas Montenegro. Miembro de número de la Academia Peruana de la Lengua (Vicepresidente), la Academia Nacional de la Historia, el Instituto Riva Agüero y el Instituto Ricardo Palma. Se ha especializado en la historia y la literatura del Perú del siglo xix. Entre otras obras ha publicado Felipe Pardo y Aliaga, La literatura del Perú del siglo xix, Perú y Ecuador. Visión actual de un antiguo conflicto, Periodismo e historia del Perú en el siglo xix, Apuntes para una historiografía de la literatura peruana del siglo xix. Ha editado las Obras completas de Manuel A. Segura. 
Los interesados en profundizar sus conocimientos sobre el periodismo peruano decimonónico se enfrentan a tal cantidad de dificultades que terminan concentrándose en períodos breves, publicaciones casi furtivas, redactores desconocidos, financiamientos interesados. Nada de lo anterior debe extrañar, pues la historia política peruana de aquellos años se ve conducida con frecuencia a enfrentar dificultades similares.

Dentro del desarrollo de la actividad periodística hay algunas épocas que son especialmente complicadas. El Perú republicano heredó el conjunto de problemas relacionados con la libertad de imprenta durante la última década virreinal y no es posible desconocer, en especial durante los años en que regía la antigua Nueva Castilla el virrey Abascal (1806-1816), las trabas que en aquellos años se imponían a la circulación de publicaciones periódicas, aunque limitaciones similares habían regido desde antes. De una u otra manera, estos problemas estaban relacionados con la libertad de prensa establecida por las Cortes de Cádiz en sus primeras sesiones y su inmediata derogatoria tan pronto como el rey Fernando VII reasume el mando ibérico ${ }^{1}$.

Entre nosotros, el problema debió haber estado vigente sin hallar una solución clara alrededor de los días de la Independencia, puesto que el Congreso Constituyente dictó el 9 de noviembre de 1823 la ley en la que se establecía la extensión de la libertad de imprenta y se determinaban cuáles eran sus abusos, se identificaba y sancionaba a los infractores y se establecía el procedimiento para tramitar las reclamaciones ${ }^{2}$. Esta ley, con algunas pequeñas modificaciones, mantuvo su

1 Véase Varillas, 2008, pp. 116-119. En el acápite 1, se pasa revista a las normas españolas relacionadas por la libertad de prensa vigente en los años finales del virreinato.

2 Con posterioridad, el inciso $7^{\circ}$ del artículo $193^{\circ}$ de la Constitución Política de 1823 establece entre las garantías constitucionales "La libertad de imprenta de conformidad con la ley que la arregle." 
vigencia hasta 1861 cuando el Congreso aprobó una nueva ley sobre la materia (28 de abril) y el presidente del Congreso la promulgó (25 de mayo), lo que confirma que sobre su texto existía algún desacuerdo, como suele ocurrir, entre el Congreso y el presidente de la república.

Pero avanzado el siglo XIX y apaciguados en algo los ánimos, quizás como consecuencia del hoy famoso y entonces terrible sermón de Bartolomé Herrera en los funerales del general Gamarra (4 de enero de 1842), cuyos tópicos repitió posteriormente en 1846, la vida peruana $-\mathrm{y}$, en consecuencia, su periodismo- generaba erróneamente la impresión de que comenzaba a reordenarse. iCuán actuales nos suenan hoy las frases de Herrera, quien, enjuiciando los trastornos de la política republicana, llamaba a la unión, al respeto hacia la autoridad legítima y a la adoración a la ley!

Sobrevivía por entonces el diario El Comercio, que databa de 1839 y que había dado cuenta de toda la competencia que había encontrado en el ámbito del periodismo; uno de ellos fue La Bolsa (1841-1842), dirigido por Manuel A. Segura; otro, el liberal $\mathrm{El} \mathrm{Correo,} \mathrm{que} \mathrm{circulaba} \mathrm{tanto} \mathrm{con} \mathrm{ese} \mathrm{nombre} \mathrm{cuanto}$ como El Correo Peruano, El Correo o simplemente Correo (1840, 1846, 1841, 1854), en el que colaboran Francisco de Paula González Vigil, Benito Laso y Francisco Javier Mariátegui; por último, El Correo de Lima que pasó a llamarse El Correo o simplemente Correo, que aparece ya en la década de 1850 (Paz Soldán, 1879, p. 400 y ss.).

Es sabido que, hacia 1848, Manuel Ricardo Palma asistía al colegio que dirigía don Antonio Marengo y que frecuentaba, también, en condición de "alumno no matriculado", el conservador Colegio de San Carlos, que dirigía Herrera. Pero el joven Palma concurría asimismo con frecuencia a la librería de Pérez, en la calle de las Mantas, sede de una animada tertulia 
político-literaria auspiciada por su propietario, gallego locuaz y chistoso (Oviedo, 1965, p. 51). Palma mismo confirma, en La Bohemia de mi Tiempo, que "deteníase largo rato en la tienda con el pretexto de cambiar las obras que algunos de sus compañeros de colegio le encomendaban" (1948, p. 59). Es decir, el futuro tradicionista, por encargo de sus jóvenes amigos, se limitaba a colaborar en el canje de los libros que Pérez les había rentado a cambio de una pequeña contraprestación económica. Por último, interesa destacar que por entonces -año 1848- hubo una estrecha relación entre todos o algunos de los concurrentes a la tertulia de la librería de Pérez, es decir, aquellos a los que con el tiempo Palma llamaría la "bohemia literaria", y el semanario El Diablo, del cual aparecieron un prospecto y doce números entre setiembre y diciembre del ya mencionado año de 1848 .

Es en ese momento en el que aparece dentro de la literatura y el periodismo nacionales don Ricardo Palma publicando en El Comercio de Lima (31 de agosto de 1848) con su nombre de entonces, Manuel Ricardo Palma, una composición A la memoria de la Sra. Da. Petronila Romero. Cuando ya maduro Palma reconstruye muchos episodios de esta parte de su vida en La Bohemia de mi Tiempo, se limita a recordar que, junto con otros bohemios, colaboraba en El Diablo, pero nada más ${ }^{3}$. Es difícil de aceptar, pese a que se ha dicho en varias ocasiones y hasta hoy se repite, que Palma llegó a dirigir El Diablo dada su ubicación intermedia entre la adolescencia y la juventud. Pero lo cierto es que desde esa edad Manuel Ricardo Palma ya había dado su primer paso dentro del periodismo nacional.

3 Es posible que en El Diablo Palma se haya desempeñado como cronista teatral principiante o haya desempeñado algún cargo de menor importancia si nos atenemos a que tres años después, en El Correo de Lima, se limitaba a ser cronista o corrector de pruebas. 
Entre este momento y junio de 1852, Palma aparentemente tenía otros intereses, pues escribe y presenta, con variado éxito, algunas obras de teatro: El hijo del sol (1849), La hermana del verdugo (1851), La muerte o la libertad (1851) y Rodil (1852). Pero, con prescindencia de su magro éxito dramático, en la tradición "Entre Garibaldi... y yo", Palma recuerda que cuando menos en parte de ese trienio ya estaba en planilla en la redacción de un periódico:

En 1851, el poeta Trinidad Fernández ${ }^{4}$ y yo, mocito de dieciocho febreros, éramos cronistas y correctores de prueba en El Correo de Lima, diario que había reemplazado a El Correo Peruano, con el pingüe sueldo de treinta pesos al mes. iQué ganga! (p. 1122).

Y ese es el momento en el que Ricardo Palma se lanza a su primera aventura periodística cuando anuncia la aparición de El Burro ${ }^{5}$.

El día de la aparición del prospecto de El Burro, 9 de junio de 1852, circulaban en Lima El Comercio (desde 1839), El Correo [de Lima] (hasta el 26 de julio pero reaparecerá en 1854), El Intérprete del Pueblo (lo hará hasta el 31 de julio) y El Playero (en el Callao y hasta fin de año). Circulaban, también, muchas publicaciones periódicas en provincias. Era aventurado, pues, salir a la calle con otra más.

4 Trinidad Fernández (1828-1873) y Palma defendían al gobierno de Echenique. Después de la batalla de La Palma (enero de 1855), Fernández se retiró de toda actividad política. Publicó dos poemarios siguiendo la tónica romántica de Fernando Velarde.

5 Las referencias a El Burro están tomadas del ejemplar que se guarda en la Biblioteca Nacional y del cual el autor de estas líneas pudo obtener copia gracias a la gentileza de su director doctor Ramón Mujica. 
Y en medio de estas publicaciones, algunas de las cuales disfrutaban de la prosperidad del gobierno del general Echenique, pero dotado de un gran entusiasmo, a principios de junio de 1852 aparece el prospecto de El Burro, el 15 de junio el primero y el 30 de junio su segundo y último número (Holguín, 1994, pp. 583-587).

Consta que el semanario pertenecía de alguna forma a Palma puesto que en 1885 , cuando el ya maduro tradicionista venía ejerciendo exitosamente la dirección de la Biblioteca Nacional, algún día debió haberse tropezado con la magra colección de $E l$ Burro y sobre ella escribe:

Fue éste el primer [roto: iperiódico?] que redacté en mis [roto: ¿días?] de colegial. Despapucho propio de un muchacho de 19 años. De buena gana quemaría hoy estas burradas. Lima, 1885. R. P.

Cuando Palma manuscribe el comentario anterior, el Prospecto y los dos números de El Burro deben haberse encontrado en buen estado de conservación; lamentablemente, casi seis décadas después, en 1943, tuvo lugar el trágico incendio de la Biblioteca Nacional que destruyó parte importante de su sección documental y se ensañó especialmente con la hemeroteca. En los años siguientes, antes de la inauguración del nuevo local de la avenida Abancay, se reconstruyeron en la medida de lo posible los restos quemados y en el caso de la hemeroteca se publicó en 1945/46 un buen catálogo. Lo que el catálogo preparado no pudo superar fue el nivel de deterioro de El Burro: el borde derecho de la colección aparece quemado y la mitad derecha de la segunda columna ha desaparecido. Por ello,

6 En su minucioso trabajo, Holguín recoge la reacción de la prensa limeña a propósito de la aparición de El Burro. 
lo que podamos decir ahora de este semanario de 27.5 por 15.2 $\mathrm{cm}$ está regido por muchas limitaciones.

El ejemplar de El Burro que existe en la Hemeroteca de la Biblioteca Nacional anduvo extraviado durante más de 20 años y fue ubicado en el año $201 \mathrm{l}$ gracias a las gestiones de su director de entonces, doctor Ramón Mujica, y de la directora del Centro de Servicios Bibliotecológicos Especializados, Lic. Doris Samanez, de las que nos complace dejar constancia.

Y puesto que ya podemos acercarnos al periodiquito que hoy nos interesa, comencemos con su Prospecto, fechado el 9 de junio de 1852. El Prospecto está encabezado por una copla en octosílabos que nos trae a la memoria otras del mismo tono de Felipe Pardo y Manuel Asensio Segura:

El Burro

En los tiempos que alcanzamos

Todo vicho [sic] es periodista,

Y periódicos hallamos

Do quier se torna la vista.

Y según lo que discurro

Si escribe hoy todo animal,

No ha de ser menos el BURRO

Que los otros ivoto a tal!

Ea! EL BURRO va a salir

$Y$ si lo quereis oir

Rebuznar este placer

Cumplido lo puede ver

Quien se venga a suscribir. 
El resto de la primera columna tampoco es digno de mayor elogio:

El BURRO será redactado por este cachazudo animal, al que ayudarán en sus tareas varios otros animales compinches suyos. Si antes no muere de congestión cerebral, se repartirá durante todos los lunes que restan de vida al año 52; y sale los lunes porque es el único día de descanso que le concede el aguador a quien pertenece.

El BURRO coceará á las mil maravillas sobre Literatura, Teatro, Modas, Relijión, Chismografia de la República y del Extranjero $\& \& \& \& \& \&{ }^{7}$ y ponga $U$. etceteras, señor Cajista, hasta que le digan pare-hermano. El $\mathrm{N}^{\circ} 1$ está fechado, tal como se prometía en el Prospecto, el 15 de junio de 1852. Su primera página está dedicada a una Asamblea de animales (que es una parodia de algún tipo de reuniones parlamentarias y se refiere a los prolegómenos de la sesión: la relación de animales integrantes, los juramentos, el inicio de la sesión). Lamentablemente, el desarrollo de la Asamblea aparece en la segunda columna que es ilegible. El número se completa con breves notas en contra de otras publicaciones que por entonces circulaban en la capital, como El Playero y el Correo cuyo sentido no puede completarse.

Aparentemente, desde su primer número El Burro ya tenía algunas dificultades, seguramente de financiamiento, a tenor de la nota con que concluye su página 4:

7 En realidad, "\&" se repite durante tres líneas consecutivas. 


\section{El Burro}

"Han convenido sus Editores en que no tenga día señalado para su aparición; porque una $\mathrm{COz}$ es bueno recibirla sin saber cuando vendrá.

El segundo número del semanario no pudo aparecer en la fecha prevista y ve la luz solo el 30 de junio. La redacción ensaya una justificación:

El Burro

Motivos imprevistos impidieron que el presente número hubiera aparecido en la anterior semana. Esperamos que nuestros suscritores perdonarán este retardo que no ha dependido, por cierto, de la voluntad de

\section{Los Redactores.}

Este número 2 y último tiene la misma estructura que el anterior: el acta de una sesión de la Asamblea de animales, ataques a El Playero, crónica teatral y una Glosa de la cual transcribimos las primeras dos estrofas:

\section{Glosa}

Un gallo en "coquericó" canta el "ut-re-sol-fa-mi"

y luego en "quiquiriquí"

le traspone un.......iqué sé yo".

La noticia me cojió

estando almorzando en casa.

Una tal Doña Damasa

fue la que me trajo el cuento

iay, señor!... Es un talento;

Un tanquam tabula rasa. 


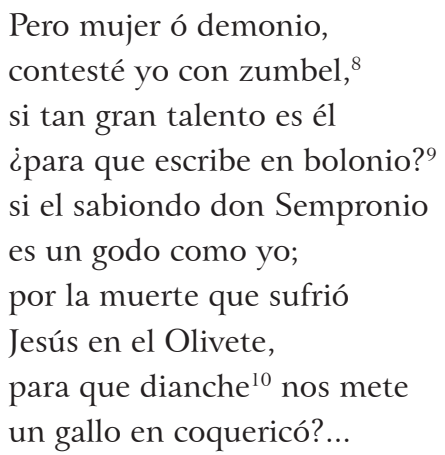

Conviene reflexionar sobre El Burro y su época. Por la anotación manuscrita antes referida, adquirimos la certeza que don Ricardo Palma era el redactor o uno de los redactores y entre ellos el de mayor importancia: no hay forma de establecer quiénes fueron los otros redactores ni quien fue el director.

En más de una ocasión se ha repetido que Palma fue el propietario de El Burro, lo que hasta la fecha no se ha podido comprobar. Es posible que con la magra remuneración que por entonces había estado recibiendo el entusiasta periodista y comediógrafo y futuro tradicionista, no haya tenido capacidad de ahorro como para enfrentar el reto. La publicación pudo haber estado financiada total o parcialmente por el gobierno de Echenique mediante la adquisición de un importante número de ejemplares, apoyo que es posible poner en duda considerando su incierta periodicidad a partir del primer número. No es posible, pues, determinar quién financió El Burro, aunque por el reiterado uso de plurales en su expresión, parecería que hubo más de un financista.

8 Zumbel: gesto ceñudo.

9 Bolonio: dícese despectivamente de los jóvenes que cursaban estudios en el Real Colegio Español de Bolonia.

10 Dianche: diantre, diablo. 
Nos hemos permitido presentar este breve comentario sobre una publicación cuyo único mérito es haber sido redactada, parcial o totalmente, por don Ricardo Palma. Entre 1850 y 1880 aparecieron en el Perú alrededor de 750 publicaciones periódicas nuevas (tenemos la impresión de que pueden haber sido más), lo que confirma que en nuestro país durante un tercio de siglo surgieron anualmente no menos de 25 periódicos nuevos. No se dispone de información suficiente, pero no hay duda de que de esa importante cantidad muchos no superaron -como es el caso de El Burro-el prospecto y los primeros números. Y es importante recordar ahora lo que advertía el propio Palma a un candidato a poeta: “...en el centro, ese es el cuento: hay que poner talento". No todas las publicaciones periódicas que aparecían hacían gala del talento que Palma requería antaño para los versos. Pero estas humildes publicaciones periódicas, individualmente poco significativas, generaban una enorme oferta de empleo urbano y eran el campo de entrenamiento para quienes pronto se habrían de incorporar de lleno a la política. Hoy, sacar una publicación de cuatro páginas no sería especialmente difícil; hace siglo y medio, los redactores, cajistas, entintadores, correctores de pruebas, prensistas, etc., daban testimonio de una actividad que demandaba una buena cantidad de personal.Pero debemos dar la vuelta al asunto. Del periodismo de aquellos tiempos no se puede esperar necesariamente ni posiciones políticas interesantes, ni datos históricos de relieve, ni testimonios de los avances literarios de un momento particular. Pero examinadas en conjunto, estas publicaciones acreditan los intereses de la ciudadanía en general, ponen de manifiesto las tremendas tensiones políticas que fueron capaces de desbaratar cualquier proyecto de desarrollo razonable, resaltan las ambiciones personales de militares y civiles y, en resumen, explican las razones por las cuales el Perú avanzó a un nivel lento y lleno de tropiezos y no logró establecer para sí un nivel de crecimiento ordenado que lo hubiera mantenido en la posición hegemónica que todos los peruanos ciertamente deseaban. 


\section{Bibliografía}

Holguín, O. (1994). Tiempos de infancia y bohemia. Ricardo Palma: 18331860. Lima: Fondo Editorial de la Pontificia Universidad Católica del Perú.

Oviedo, J. M. (1965). Genio y figura de Ricardo Palma. Buenos Aires: EUDEBA.

Palma, R. (1948). La bohemia de mi tiempo. Lima: Hora del Hombre.

Paz Soldán, M. F. (1879). Biblioteca Peruana. Lima: Imprenta Liberal.

Varillas, A. (2008). El periodismo en la historia del Perú. Desde sus orígenes hasta 1850. Lima: Fondo Editorial de la Universidad de San Martín de Porres.

Recibido el 04 de febrero del 2019 Aprobado el 05 de febrero del 2019 